\title{
Twelve Tips for Successful Use of "Clickers" in the
}

\section{Classroom}

Yera Hur

Medical Education Center, Inha University School of Medicine, Incheon, Korea

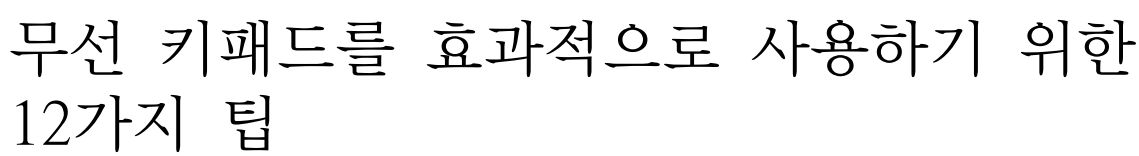

인하대학교 의학전문대학원 의학교육실

허예라

최근 여러 의학교육 현장에서 “clicker”라 불리는 무선 키패드를 활용하고 있다. 특히, 교수자들은 무선 키패드 를 활용하여 학생들의 수업 참여도를 높이고, 가르치고 있는 내용의 이해 정도를 점검하거나 특정한 문제에 대 한 학생들의 반응을 살펴보거나 학습한 내용에 대한 간 단한 평가를 받아 보는 등 간단한 설문 응답부터 형성 평가와 종합평가의 결과를 즉각적으로 수집하고 있다. 다음은 수업에서 학생들을 대상으로 활용하는 무선 키 패드(student response system, SRS)를 보다 효과적으 로 사용하기 위한 12 가지 팁에 대한 설명이다.

\section{Tip 1. Pedagogy should be the focus-not the technology}

학습자들의 집중력이 수업 시작 후 15 20분 후 떨어 지므로 이 시점에서 $\mathrm{SRS}$ 를 활용하거나 학습자들 간 토 의수업을 진행시킬 수 있다. 이렇게 20분 간격으로 학 습 분위기에 변화를 줄 수 있는데, 이 과정이 수업 흐름 에 방해가 되지 않도록 질문의 연관성을 유지해야 한다.

\section{Tip 2. Check your readiness for using this strategy}

$\mathrm{SRS}$ 는 사전 준비와 시간적 노력이 필요한 학습도구
이다. 장비를 사용할 줄 알아야 함은 물론 질문들도 미 리 작성해 두어야 한다. 또한 컴퓨터가 다운되거나 갑 자기 기계가 작동을 안 하는 등 기술적인 문제는 언제 든지 발생할 수 있으므로, SRS가 오작동 했을 경우에 대처방안도 미리 생각해 두어야 한다.

\section{Tip 3. Practice using the technology-learn to input questions ahead of time and on the fly}

SRS의 활용방법을 제대로 알아야 한다. 예) 선다형, 네/아니오, 순위 질문 등. 때로는 수업 중에 필요한 질 문을 즉흥적으로 만들고자 하는 경우도 있을 수 있으므 로 도구 사용법을 미리 익혀두어야 한다. 예) 학생들의 이해도 점검을 통해 진도를 계속 나갈지를 결정.

Tip 4. Identify purpose of posing questions 토의를 위한 질문은 학습자가 동의 또는 동의하지 않

Korean J Med Educ 2009 Jun; 21(2): 195-196. doi: $10.3946 / \mathrm{kjme.2009.21.2.195.}$

(C) The Korean Society of Medical Education. All rights reserved. 
는 형식으로 답할 수 있도록 해야 하며, 형성평가 문제 일 경우 수업목표와 직접적인 연관이 있는 내용으로 구 성해야 한다.

- 이 질문이 내 수업 목표와 어떻게 연관되어 있는가?

- 이 질문을 통해 내가 얻고자 하는 것은 무엇인가?

\section{Tip 5. Less is better than more}

얼마나 많은 질문을 사용해야 하는가에 대한 대답은 $\mathrm{SRS}$ 를 어떤 목적으로 수업에 활용하느냐에 따라 다르 다. 예) 60 분 강의 수업에서 학생들의 적극적인 참여를 유도하고자 할 경우 $3 \sim 4$ 개의 질문 (20분 간격)이 적절 하다. 그러나 SRS를 매 수업마다 활용하면 교수자도 학 습자도 지칠 수 있으므로 SRS 외에 다양한 교수 · 학습 전략도구를 활용하는 것이 바람직하다.

\section{Tip 6. Write the question and test it}

- 기술적인 이유: 응답이 수신 장치로 제대로 수신이 되는지 확인

- 교육적인 이유: 문항의 신뢰도 확인 및 전문가에게 타당도 확인

\section{Tip 7. Plan for contingency teaching}

다양한 문제를 준비하여 학습자의 응답 결과에 따라 일부 학습 내용을 보다 자세히 다루거나 넘어갈 수도 있다.

\section{Tip 8. Build in time for the activity}

각 문제 당 평균적으로 $3 \sim 5$ 분의 소요시간을 계산하 도록 한다. 동료와 토의 후 다시 응답하게 하는 활동에 서는 더 많은 시간을 소요할 수도 있고, 시험문제를 푸 는 경우 소요 시간을 줄일 수도 있지만 최소한 2 3분은 계획하도록 하고, 키패드 배포/수거 시간도 미리 계산 하도록 한다.

Tip 9. Decide if individuals have to be linked to questions or not

단순한 수업참여 유도가 아닌 평가를 위한 문제를 낼
경우, 응답기에 번호를 매기고 해당 응답기에 대응하는 학생명단 및 기타 필요한 사항들을 미리 만들어 두는 것이 좋다.

\section{Tip 10. Decide on whether you want to use the output or not}

수집된 정보를 어떻게 분석하고 활용할 것인지에 대 한 계획을 미리 해야 한다.

- 학습자들 간 또는 수업 간의 응답을 서로 비교하고 싶은가?

- 연구의 목적으로 활용할 것인가?

- 성별이나 나이에 따라 응답에 차이가 있는가?

\section{Tip 11. Evaluate effectiveness}

$\mathrm{SRS}$ 활용의 효과는 문제의 질과 양 그리고 사용 목적 에 따라 달라진다. 수업 중 $\mathrm{SRS}$ 를 활용했던 중간고사와 기말고사 평가 결과를 보면 SRS의 효과를 증명할 수 있 다.

- 학습자들의 학습결과를 향상시키기 위해 SRS를 어 떻게 활용할 수 있는가?

\section{Tip 12. Enjoy the process, be creative}

해당 수업의 내용과 환경에 적절하고 교수자 자신이 $\mathrm{SRS}$ 활용이 용이하게 느껴지고 즐길 수 있을 때에만 사 용하는 것이 바람직하다. 대학에서 기계를 구입했다는 이유만으로 교수자들에게 SRS 사용을 강요해서는 안 된다.

- SRS가 내 수업에서 학습자들의 학습을 촉진시킬 수 있는 가장 좋은 방법인가?

- 나와 학생들은 SRS를 즐기고 있는가?

\section{REFERENCES}

Premkumar K, Coupal C. Rules of engagement-12 tips for successful use fo "clickers" in the classroom. Med Teach 2008; 30: 146-149. 